\title{
The Data Protection Officer: Profession, Rules and Role
}

\section{(Routledge, Taylor and Francis)}

\section{Dr Paul Lambert}

\section{CHAPTER 2:}

\section{NEW PROFESSION}

\section{INTRODUCTION}

Chapter IV, Section 4 of the new General Data Protection Regulation creates the new professional role of and requirement for organisations to designate a formal Data Protection Officer for the organisation. There are rules in relation to:

- $\quad$ organisations' designation of the Data Protection Officer;

- $\quad$ groups of undertakings and the appointment of a single Data Protection Officer;

- the appointment of a single Data Protection Officer by public bodies or public authorities.

This essentially creates a new profession, perhaps one of a number of new professions and career paths in relation to data protection issues and the new data protection regime. This emphasises the new importance attached to personal data.

Chapter IV, Sections 4 and 5 of the new General Data Protection Regulation contains Articles 37 to 42 . Specifically, these relate to:

- $\quad$ the designation of the Data Protection Officer (Article 37);

- $\quad$ position of the Data Protection Officer (Article 38);

- $\quad$ the tasks of the Data Protection Officer (Article 39);

- $\quad$ codes of conduct (Article 40);

- $\quad$ certification (Article 42);

The Data Protection Officer will be chosen on the basis of professional qualities and in particular expert knowledge of data protection law and practices and the ability to fulfil the tasks (Article 37(5)).

The Data Protection Officer will have expert knowledge of data protection law and practices, including:

- regulations;

- $\quad$ technical and organisations measures and procedures; 
- $\quad$ expertise on technical requirements for data protection by design, by default and data security;

- $\quad$ industry and sector specific knowledge;

- $\quad$ experience with the size of the controller or processor;

- $\quad$ aware of the sensitivity of the data processed;

- $\quad$ ability to carry out inspections, consultation, documentation and analysis (including outsourcing or delegating);

- $\quad$ ability to work with data subject and employees' representation organisations;

- $\quad$ the organisation must enable the Data Protection Officer to take part in ongoing advanced training measures to maintain specialised knowledge.

\section{DESIGNATION OF DATA PROTECTION OFFICER}

The organisation's new Data Protection Officer should have professional qualities, expertise and experience and a particular expert knowledge of data protection law and practice.

They need to have the ability to understand and fulfil their tasks under the General Data Protection Regulation and national data protection law.

The Data Protection Officer may be an employee of the organisation or a contractor.

The contact details for the new Data Protection Officer needs to be made public.

These contact details should also be sent to the national data protection supervisory authority.

The designation of a Data Protection Officer is required in any case where:

- $\quad$ The processing is by a public authority or body (except courts);

- The core activities consist of processing which by virtue of nature, scope and or purpose require "regular and systematic monitoring of data subjects on a large scale"; or

- The core activities of the controller or processor on a large scale of special categories of data pursuant to Article 9 and personal data relating to criminal convictions and offences referred to in Article 10.

\section{INDEPENDENCE}

Article 38 (Position of the Data Protection Officer) states that:

"The controller and the processor shall ensure that the Data Protection Officer is involved, properly and in a timely manner, in all issues which relate to the protection of personal data."

Also,

"The controller and the processor shall support the Data Protection Officer in performing the tasks ... by providing resources necessary to carry out those tasks and access to personal data and processing operations, and to maintain his or her knowledge." 
Importantly,

"The controller or processor shall ensure that the Data Protection Officer does not receive any instructions regarding the exercise of those tasks. He or she shall not be dismissed or penalised by the controller or the processor for performing [the] tasks. The Data Protection Officer shall directly report to the highest management level of the controller or the processor."

It is expressly made clear that the Data Protection Officer "shall ... not receive any instructions regarding the exercise of [the] tasks." This means that the organisation shall not interfere in or pressure the Data Protection Officer in carrying out and exercising their tasks. The Data Protection Officer is effectively independent in undertaking their tasks.

The Data Protection Officer is also independent in being free from direction or reporting requirements to other staff, managers, section heads or particular product or service project managers. This means that the Data Protection Officer cannot be pressured into approving certain activities or projects when certain doubts may exist as regards a new (or existing) data collection or processing activity. Equally, the Data Protection Officer should be not pressured into ignoring a data protection analysis of new (or existing) activities which may raise data protection compliance concerns.

\section{CANNOT BE DISMISSED OR PENALISED FOR DOING JOB}

Article 38 (Position of the Data Protection Officer) states that:

"[The Data Protection Officer] shall not be dismissed or penalised by the controller or the processor for performing [the] tasks."

It is clear therefore that a significance, independence, insulation and protection is being afforded to the new role of the Data Protection Officer.

Once the Data Protection Officer is undertaking their official role and tasks, the organisation cannot victimise, dismiss or penalise the Data Protection Officer.

It is more of an open issue as to whether sanctions can arise in relation to data protection tasks and or other issues. However, given the possibility of threats, implicit threats and constructive dismissal, it may well be difficult - if not impossible - to impose sanctions in relation to core data protection tasks, duties and functions. It may seem easier to impose sanction for purported errant activity which is outside of or unrelated to the core tasks and activities of the Data Protection Officer. This may be difficult to demonstrate in practice, however, if there is a possibility of this other activity being referred to as a tacit punishment stemming from something occurring or not occurring in the data protection sphere. It may prove in practice to be difficult to disassociate data and other functions, with consequent effects.

This is in order to assist and ensure the independence of the Data Protection Officer in carrying out their tasks, and in order to ensure they have the confidence to be able 
to undertake and follow through on their tasks, without impermissible pressure, third party interference, or unwarranted direction or intimidation.

However, it should be noted that it may be permitted for the Data Protection Officer to undertake tasks and duties other than data protection related tasks. If there are any other tasks, or duties, they must "not result in a conflict of interests." It might be argued that the insulation and protection afforded to the Data Protection Officer may not extend to disciplinary procedures as regards these non data protection related activities. However, it is noted that the provision states the Data Protection Officer "shall not be dismissed or penalised ... for performing [the] tasks" suggesting possible dismissal or performing the tasks or in relation to other non personal data tasks. The reference to duties ad tasks does not necessary distinguish as between the different duties and tasks of the Data Protection Officer (referring only to "[the] tasks" in Article 38(3)). It can quite likely be said that the protection that the Data Protection Officer may not be dismissed regardless of data protection and non data protection tasks and duties, or at least that an organisation may have a most difficult task in seeking to justify a particular sanction or dismissal.

\section{REPORTING LINE}

Article 38 (Position of the Data Protection Officer) states that:

"The Data Protection Officer shall directly report to the highest management level of the controller or the processor."

It is clear, therefore, that a significance is being afforded to the new role of the Data Protection Officer.

Again, this assists and ensures the independence of the Data Protection Officer in carrying out their tasks, and in order to ensure they have the confidence to be able to undertake and follow through on their tasks, without impermissible pressure, third party interference, or unwarranted direction or intimidation.

\section{DATA PROTECTION OFFICER}

There may have been a traditional view within organisations that the role of the person tasked with dealing with data protection issues was limited to dealing with outward facing data protection queries such as access requests, data protection website queries and the like. There may have been an understanding that human resource managers were responsible for dealing with all employee related queries, including references to and copies of employee documentation and personal data.

This is no longer the case. Now there must be a designated Data Protection Officer appointed in organisations. Furthermore, the role and tasks of the Data Protection Officer is not limited to outward facing issues. The Data Protection Officer will also be concerned with inward facing issues. Employees and similar internal facing individuals have data protection rights and will be able to address queries to the Data Protection Officer quite separate from the human resource functions.

Therefore, organisations must consider Data Protection Officer issues and the General Data Protection Regulation in terms of internal facing functions. Chapter IV, 
Section 4 of the new General Data Protection Regulation refers to Data Protection Officers and the obligation for organisations to appoint Data Protection Officers.

The controller and the processor shall designate a Data Protection Officer in any case where:

- $\quad$ The processing is by a public authority or body;

- $\quad$ The core activities involve processing with "regular and systematic monitoring of data subjects on a large scale"

- $\quad$ The core activities involve processing with special categories of data or criminal convictions or offences data on a large scale. ${ }^{1}$

A group of undertakings may appoint a single Data Protection Officer. ${ }^{2}$

Where the controller or the processor is a public authority or body, a single Data Protection Officer may be designated for several such authorities or bodies, taking account of their organisational structure. ${ }^{3}$

In cases other than those referred to in Article 37(1), the controller or processor or associations and other bodies representing categories of controllers or processors may designate a Data Protection Officer. ${ }^{4}$

The Data Protection Officer shall be designated on the basis of professional qualities and, in particular, expert knowledge of data protection law and practices and the ability to fulfil the tasks referred to in Article 39. In some instances, therefore, the necessary level of expert knowledge may be determined, inter alia, according to the data processing carried out and the protection required for the personal data processed by the organisation.

The Data Protection Officer may be a staff member of the controller or processor, or fulfil the tasks on the basis of a service contract. ${ }^{5}$

The controller or the processor shall publish the contact details of the Data Protection Officer and communicate these to the supervisory authority. ${ }^{6}$

The controller or the processor shall ensure that the Data Protection Officer is involved properly and in a timely manner in all issues which relate to the protection of personal data.

The controller or processor shall ensure the Data Protection Officer performs the tasks and duties independently and without instructions regarding the exercise of the functions. ${ }^{8}$

GDPR art 37(1)

GDPR art 37(2).

GDPR art 37(3).

GDPR art 37(4).

GDPR art 37(6).

GDPR art 37(7).

GDPR art 38(1).

GDPR art 38(3). 
Data subjects may contact the Data Protection Officer on all issues related to the processing of the data subject's personal data and the exercise of their rights under the General Data Protection Regulation. ${ }^{9}$

The controller or processor shall support the Data Protection Officer in performing the tasks and shall provide the resources needed to carry out the duties and tasks. ${ }^{10}$ This could include, for example, staff, premises and equipment.

The Data Protection Officer shall have at least the following tasks:

- $\quad$ to inform and advise the controller or the processor and the employees who carry out processing of their obligations pursuant to the Regulation and to other Union or Member State data protection provisions;

- $\quad$ to monitor compliance with the Regulation, with other Union or Member State data protection provisions and with the policies of the controller or processor in relation to the protection of personal data, including the assignment of responsibilities, awareness-raising and training of staff involved in processing operations, and the related audits;

- to provide advice where requested as regards the data protection impact assessment and monitor its performance pursuant to Article 35;

- $\quad$ to cooperate with the supervisory authority;

- $\quad$ to act as the contact point for the supervisory authority on issues relating to processing, including the prior consultation referred to in Article 36, and to consult, where appropriate, with regard to any other matter. ${ }^{11}$

Importantly, the Data Protection Officer shall in the performance of the tasks have due regard to the risk associated with processing operations, taking into account the nature, scope, context and purposes of processing. ${ }^{2}$

\section{QUALIFICATIONS AND EXPERTISE OF DATA PROTECTION OFFICER}

The Data Protection Officer shall be designated on the basis of professional qualities and, in particular, expert knowledge of data protection law and practices and the ability to fulfil the tasks referred to in Article $39 .^{13}$

The Data Protection Officer may be a staff member of the controller or processor, or fulfil the tasks on the basis of a service contract. ${ }^{14}$

\section{INDEPENDENT IN ROLE AND FUNCTIONS}

The controller or processor shall ensure that the Data Protection Officer does not receive any instructions regarding the exercise of these functions. They shall not be dismissed by the controller or the processor for performing their functions. ${ }^{15}$

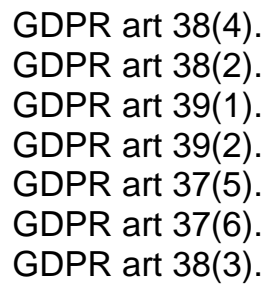




\section{RESOURCES}

The controller and processor shall support the Data Protection Officer in performing the tasks and functions. The controller or processor as appropriate shall provide resources necessary to carry out the duties and tasks, ${ }^{16}$ which may include, for example, staff, premises, equipment and any other resources There is, therefore, a protection against under-resourcing, even deliberate under-resourcing, of the Data Protection Officer.

\section{DESCRIPTION}

Organisations must designate a Data Protection Officer, including:

- to monitor internal compliance with the General Data Protection Regulation regime and rules;

- $\quad$ where the processing is undertaken in the public sector; or

- where the processing requires regular and systematic monitoring of data subjects;

- $\quad$ to ensure governance of the organisation's data management;

- $\quad$ to draft, review and update compliant data protection policies;

- $\quad$ to implement systems, changes and functions in terms of being compliant.

The Data Protection Officer should be qualified and have particular expertise in data protection law and practice. There is a need to be able to fulfil their tasks in compliance and conformity with the General Data Protection Regulation. It appears they may be an employee or a contractor.

The Data Protection Officer details must be made available publicly and the supervisory authority should be notified.

The organisation must involve the Data Protection Officer timely in relation to all issues relation to the protection of personal data and Data Subject issues, proper and adequate resources must be supplied to the Data Protection Officer by the organisation in order that they can undertake their tasks. There is an obligation that the Data Protection Officer has independence in their role and functions, and that they cannot be controlled or micro-managed or instructed in relation to their tasks.

The Data Protection Officer will report to the board or highest management level as appropriate. This also emphasises the increasing importance attached to data protection understanding and compliance.

The Data Protection Officer advises the organisation and employees in relation to their data protection obligations under national law and the General Data Protection Regulation. They will also monitor compliance with the data protection legal regime as well as internal policies. They will also be involved in assigning responsibilities, raising awareness and staff education and training.

16 GDPR art 38(2). 
Data Protection Officers should be highlighting the changes and the new General Data Protection Regulation to the organisation. Key issues need to be identified to appropriate management. New and ongoing change and compliance issues need appropriate resourcing. The Data Protection Officer should assess what personal data the organisation collects and processes, for what purpose, and where it is located and secured. Particular attention is need with outsourcing issues and contracts with processors. Contracts, including service level agreements in relation to IT systems, cloud, etc may be assessed. The various IT hardware, software and systems that employees use need to be considered.

The structure of the organisation of groups need to be considered, as well as jurisdiction and location issues. The life cycles, storage and disposal of personal data is also an important consideration for the new Data Protection Officer.

The processes, policies and documentation must be maintained by the organisation, which places particular obligations on the Data Protection Officer, to consider the different documentation sets. 